\title{
HCN-Free Hydrocyanation of Alkenes
}

Conditions A:

$$
\begin{aligned}
& \text { 1. } \mathrm{H}_{2} \text { (5 bar), } \mathrm{CO} \text { (5 bar), } \\
& \mathrm{Rh} \text { (acac) }(\mathrm{CO})_{2} \text { (1.0 mol\%), } \\
& \text { L1 or L2 (3.0 mol\%), } \mathrm{PhCO}_{2} \mathrm{H} \text { (10 mol\%), } \\
& 1 \text {-aminopiperidine (3.0 equiv) } \\
& \mathrm{R}^{1} \mathrm{R}^{2} \\
& \text { THF } 60^{\circ} \text {, } 24 \text { h } \\
& \text { 2. MMPP. } 6 \mathrm{H}_{2} \mathrm{O} \text { (2.0 equiv) } \\
& 0^{\circ} \mathrm{C}, 9 \mathrm{~min}
\end{aligned}
$$

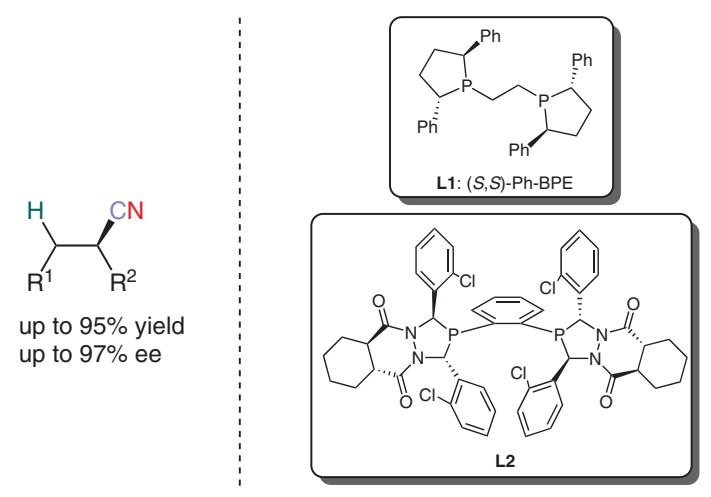

L2

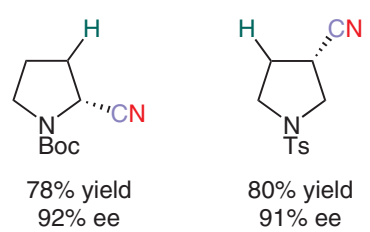

\section{Category}

Metals in Synthesis

\section{Key words}

asymmetric synthesis

hydrocyanation

rhodium catalysis

\section{Synfact 1

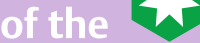 Month}

Conditions B:
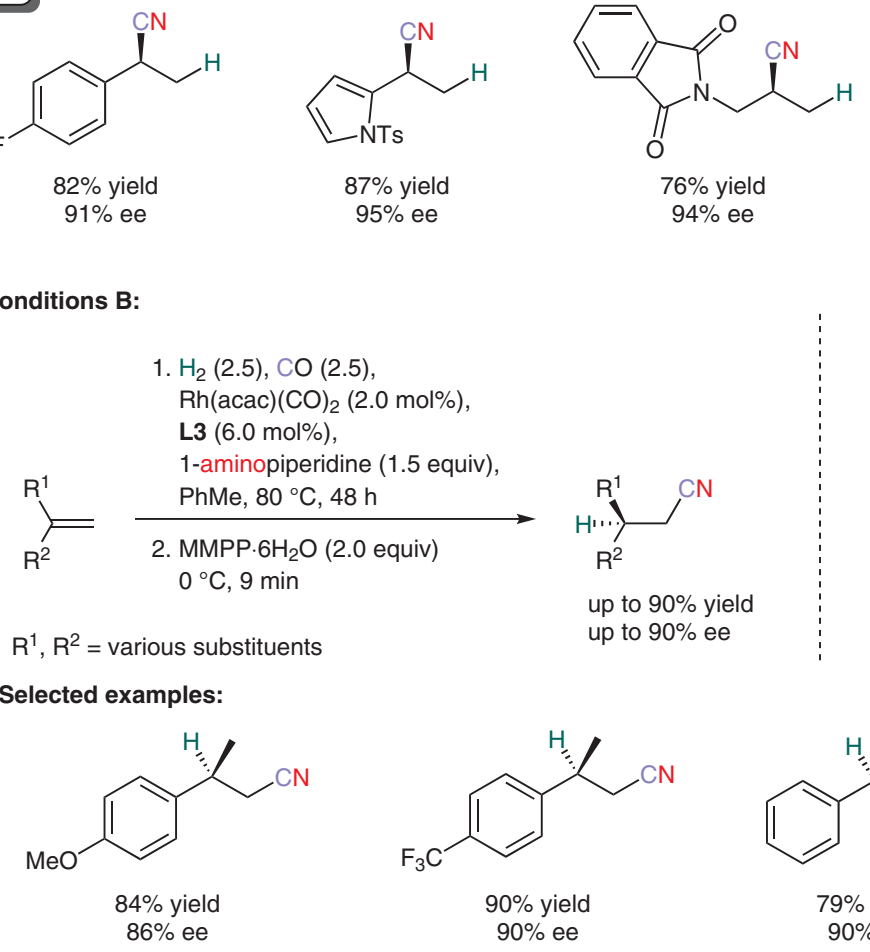

Significance: The authors developed an asymmetric rhodium-catalyzed HCN-free formal hydrocyanation of various functionalized 1,2- and 1,1disubstituted alkenes. Depended on the alkene, various chiral ligands are necessary to afford the corresponding chiral products in high enantioselectivities.
Comment: The formal asymmetric hydrocyanation proceeds via an asymmetric hydroformylation and subsequent acid-catalyzed imine formation with 1-aminopiperidine. An aza-Cope elimination induced by addition of MMPP affords the corresponding chiral nitrile. 